\title{
Determinant Factors of Sleep Quality Disorder Among Nurse in Tabanan General Hospital Year 2018
}

\author{
N K L M Sandhi ${ }^{1}$ and S Harkitasari ${ }^{1 *}$ \\ ${ }^{1}$ Faculty of Medicine and Health Sciences, Universitas Warmadewa, Denpasar, Bali \\ *saktiviharkitasari85@gmail.com
}

\begin{abstract}
Sleep is one of the primary needs of the basic requirement for human survival. Sleep disorders can cause some effect in humans. It is estimated that $60-80 \%$ of workers with shift work system have impaired sleep quality. This results in a decrease in work productivity and an increase in the occurence of accidents. This study aims to determine the determinants of sleep quality disorders nurses in Tabanan General Hospital. This study used cross sectional analytical observational method by conducting questionnaire based interview. The study population was nurses in Tabanan General Hospital with sampling using consecutive sampling technique with samples of 94 people. The results of this study found that factors that have a statistically significant relationship with the quality of sleep is married / have a marital status ( $P R=5,53$, IK 95\%: 1,50-20,39, $p$ $<0,05$ ), nurses with tollders ( $\mathrm{PR}=3,88$, IK 95\%: 1,28-11,71, $\mathrm{p}<0,05$ ) and work system shift $(\mathrm{PR}=19,46$, IK 95\%: 2,48-152,69, $\mathrm{p}<0,05)$. While the factors that have not statistically significant relationship were sleeping environment $(\mathrm{PR}=2,06$, IK 95\%: $0,72-5,91, \mathrm{p}=0,17)$ and coffee consumption in high quantities $(\mathrm{PR}=1,41, \mathrm{IK} 95 \%: 0,53$ $3,73, p=0,48)$. Based on the result of research, it is found that marital status, toddler ownership and work system are the determinants of nursing sleep quality disorder in Tabanan General Hospital.

Keyword : Determinant, Quality, General Hospital
\end{abstract}

\section{Introduction}

Sleep is an unconscious state where the individual's perceptions and reactions to the environment decrease or disappear, and can be reawakened with provocation [1]. According to the National Sleep Foundation, adults need to sleep 7-9 hours to gain good and quality sleep in a day [2]. Without adequate and quality sleep, brain function abilities will deteriorate rapidly and cause prolonged sleep during the day, fatigue, irritability, impaired physical and mental performance, depression, heart disease, hypertension and obesity [3].

One of the things that is of concern is that $60-80 \%$ of workers with the shift working system experience impaired sleep quality [1]. Workers in the medical department, especially nurses, are workers with a high tendency to experience impaired sleep quality. Female nurses in the North Taiwan region have poor sleep quality of $75.8 \%$ [4]. While in Indonesia the percentage of nurses who experience sleep quality disorders is as much as $55.77 \%$ at the Prof. Dr. R. D Kandou Central General Hospital, Manado [1]. The research conducted at the Abdul Moelek Regional General Hospital Bandar Lampung found nurses who had disturbed sleep patterns with shift system of $84.3 \%$ and non-shifts of $15.6 \%$ [5].

According to the International of Sleep Disorder data, the causes of sleep disorders are Restless Legs Syndrome by 5-15\%, alcohol dependence by $10 \%$, late sleep syndrome by 5$10 \%$, depression by $65 \%$ and shift work by $57 \%$ [4]. Shift work is thought to affect the quality 
of sleep in nurses, especially night shifts. As many as $60 \%$ of nurses sleep for approximately 6 hours experiencing a decrease in the quality and quantity of sleep. In the research at Prof. Dr. R. D Kandou Central General Hospital Manado, it was found that as many as $59.62 \%$ of nurses who were married tended to experience higher sleep quality disorders due to increased family responsibilities [1].

Lower sleep quality of the nurses can have an impact on the nurse's theirselves as well as on the patients they treat. In addition to reducing work ability, the chances of a medical error will also increase. Medical errors that can occur include lowering the ability to remember important information from patients, difficulty in making a decision quickly, interpreting the intentions of a speech and having an inappropriate emotional response [4]. The Tabanan General Hospital or Badan Rumah Sakit Umum Tabanan (BRSU) is one of the governmentowned hospitals as a health service center in Tabanan Regency. Medical personnel, especially nurses who are always ready to handle patients, are needed to provide good health services to the community. The researcher conducted an initial survey of 10 nurses at the BRSU Tabanan by interviews. As many as 8 people said that they often experience fatigue and difficulty concentrating when handling patients, 6 nurses complained of having sleep quality impairments due to night shift work and marital status that made their time to rest limited. From the interviews, it can be concluded that nurses have a tendency to experience impaired sleep quality. Based on this, the researchers were interested in finding out the determinants of the impaired sleep quality of the nurses at the BRSU Tabanan.

\section{Method}

\subsection{Data Collection}

This study used a cross sectional observational research method to determine the relationship of the determinants of impaired sleep quality of nurses at the BRSU Tabanan. The sample selection is done non-randomly by consecutive sampling technique that is by setting a subject that meets the research criteria until the required number of samples is fulfilled. While the dependent variable is the quality of sleep. Sleep quality variables were measured using the Pittsburgh Sleep Quality Index questionnaire with good sleep quality categories if the score <5 and poor sleep quality if score $\geq 5$. Data collection was done using interview-based questionnaires to respondents.

\subsection{Statistical Analysis}

The process of data analysis uses a statistical analysis computer program (SPSS). Data analysis was carried out in two stages, namely descriptive statistical stage to determine the baseline characteristics of the research subjects and the analytical statistics stages to calculate the prevalence ratio (PR) with a confidence interval (CI) of 95\%. Hypothesis testing for bivariate analysis with independent and dependent variables with a nominal scale using the Chi-Square method is said to be significant if the value is $\mathrm{p}<0.05$.

\subsection{Ethical Consideration}

The study, the collection of clinical and epidemiological data submitted for ethical approval to the Research Ethic Committee of Udayana University, Denpasar. Enrollment of the study participants is conditional on appropriate consent. 


\section{Results And Discussion}

Table 1 shows that subjects younger than 30 years old as many as $52(55.32 \%)$ people and subjects at the age of $\geq 30$ years was 42 people (44.68\%) people. Male subjects amounted to 37 $(39.36 \%)$ subjects and female was 57 subjects $(60.64 \%)$. Based on the level of education obtained the number of subjects with diploma education level as many as $55(58.52 \%)$ people and scholars as many as $49(41.48 \%)$ people

Table 1. Baseline Characteristics of Research Subjects

\begin{tabular}{lcc}
\hline \multicolumn{1}{c}{ Characteristics } & Frequency & Percentage \\
\hline Age & & \\
$\quad<30$ years old & 52 & $55.32 \%$ \\
$\quad \geq 30$ years old & 42 & $44.68 \%$ \\
Gender & & \\
$\quad$ Male & 37 & $39.36 \%$ \\
$\quad$ Female & 57 & $69.64 \%$ \\
Education background & & \\
$\quad$ Diploma & 55 & $58.52 \%$ \\
$\quad$ Graduate & 49 & $41.48 \%$ \\
Working period (years) & & \\
$\quad \leq 5$ years & 56 & $59.57 \%$ \\
$\quad>5$ years & 38 & $40.43 \%$ \\
Economic status & & \\
$\quad$ High & 39 & $41.48 \%$ \\
$\quad$ Low & 55 & $58.52 \%$ \\
\hline
\end{tabular}

Based on the working period, it was found that subjects with a working period of less than 5 years were $56(59.57 \%)$ people and $>5$ years working period of $38(40.43 \%)$. Based on economic status, the number of subjects with low economic status was $39(48.48 \%)$ people and high economic status was $55(58.52 \%)$ people.

Table 2. Relationship between Marital Status and Sleep Quality

\begin{tabular}{lllcll}
\hline \multirow{2}{*}{ Variable } & \multicolumn{2}{c}{ Sleep Quality } & \multicolumn{2}{c}{ PR } & \multirow{2}{*}{ P } \\
\cline { 2 - 4 } & & \multicolumn{1}{c}{ Good } & Poor & IC $\%$ & \\
\hline Marital & Married/having partner & $18(33.93 \%)$ & $38(66.07 \%)$ & 5.53 & $<0.05^{*}$ \\
Status & Single/no partner & $3(7.9 \%)$ & $35(92.10 \%)$ & $(1.50-20.39)$ & \\
\hline
\end{tabular}

*: statistically significant

Marital status has a statistically significant relationship with sleep quality with a PR value of 5.53, 95\% CI: $1.50-20.39, \mathrm{p}<0.05$. This means that subjects who are married / having a partner have a risk of 5.53 times experiencing poor sleep quality compared to subjects who are unmarried/no partner. So it can be concluded that the hypothesis of this study was accepted.

Table 3. Toddler-ownership Bivariate Analysis with Sleep Quality

\begin{tabular}{|c|c|c|c|c|c|}
\hline \multirow{2}{*}{\multicolumn{2}{|c|}{ Variable }} & \multicolumn{2}{|c|}{ Sleep Quality } & \multirow{2}{*}{$\begin{array}{c}\text { PR } \\
\text { IC 95\% }\end{array}$} & \\
\hline & & Good & Poor & & \\
\hline Toddler & Having toddler & $16(32.65 \%)$ & $33(67.35 \%)$ & 3.88 & $<0.05^{*}$ \\
\hline
\end{tabular}




\begin{tabular}{|c|c|c|c|c|c|}
\hline \multirow{2}{*}{\multicolumn{2}{|c|}{ Variable }} & \multicolumn{2}{|c|}{ Sleep Quality } & \multirow{3}{*}{$\begin{array}{c}\text { PR } \\
\text { IC 95\% } \\
(1.28-11.71)\end{array}$} & \multirow{3}{*}{$\mathbf{P}$} \\
\hline & & Good & Poor & & \\
\hline Ownership & No toddler & $5(11.11 \%)$ & $40(88.89 \%)$ & & \\
\hline
\end{tabular}

*: statistically significant

The results of bivariate analysis of sleep quality with toddler ownership had a relationship that was statistically significant. From the results of the analysis, the PR value is $3.88,95 \%$ IC: $1.28-11.71, \mathrm{p}<0.05$. This means that subjects who do not have toddlers have a risk of 3.88 times experiencing poor sleep quality compared to subjects who have toddlers.

Table 4. Toddler-ownership Bivariate Analysis with Sleep Quality

\begin{tabular}{|c|c|c|c|c|c|}
\hline \multirow{2}{*}{\multicolumn{2}{|c|}{ Variable }} & \multicolumn{2}{|c|}{ Sleep Quality } & \multirow{2}{*}{$\begin{array}{c}\text { PR } \\
\text { IC } 95 \%\end{array}$} & \multirow{2}{*}{$\mathbf{P}$} \\
\hline & & Good & Poor & & \\
\hline Work system & $\begin{array}{l}\text { Shift } \\
\text { Non-shift }\end{array}$ & $\begin{array}{l}20(35.09 \%) \\
1(3.70 \%)\end{array}$ & $\begin{array}{l}37(64.91 \%) \\
36(97.30 \%)\end{array}$ & $\begin{array}{c}19.46 \\
(2.48-152.69)\end{array}$ & $<0.05^{*}$ \\
\hline
\end{tabular}

*: statistically significant

The results of the analysis of work system analysis with sleep quality have a relationship that is statistically significant with a PR value $=19.46,95 \%$ CI: $2.48-152.69, \mathrm{p}<0.05$. This means that subjects with shift work systems have a risk of 19.46 times experiencing poor sleep quality compared to subjects with non-shift work systems. So that it can be concluded that the research hypothesis is accepted.

Table 5. Bivariate Analysis of Sleep Quality with the Sleep Environment

\begin{tabular}{|c|c|c|c|c|c|}
\hline \multirow{2}{*}{\multicolumn{2}{|c|}{ Variable }} & \multicolumn{2}{|c|}{ Sleep Quality } & \multirow{2}{*}{$\begin{array}{c}\text { PR } \\
\text { IC 95\% }\end{array}$} & \multirow{2}{*}{$\mathbf{P}$} \\
\hline & & Good & Poor & & \\
\hline Sleep & Not Comfortable & $6(15.38 \%)$ & $33(84.62 \%)$ & 1.14 & 0.48 \\
\hline environment & Comfortable & $15(27.27 \%)$ & $40(72.73 \%)$ & $(0.53-3.73)$ & \\
\hline
\end{tabular}

The results of the analysis of sleep environment and sleep quality had a relationship that was not statistically significant with a PR value $=2.06,95 \% \mathrm{CI}$ : $0.72-5.91, \mathrm{p}=0.17$. Based on the value of the confidence interval which includes number 1, the sleep environment cannot be concluded as a risk factor for the quality of poor sleep in nurses.

Table 6. Bivariate Analysis of Sleep Quality with Coffee Consumption

\begin{tabular}{|c|c|c|c|c|c|}
\hline \multirow{2}{*}{\multicolumn{2}{|c|}{ Variable }} & \multicolumn{2}{|c|}{ Sleep Quality } & \multirow{2}{*}{$\begin{array}{c}\text { PR } \\
\text { IC 95\% } \\
\end{array}$} & \multirow[t]{2}{*}{$\mathbf{P}$} \\
\hline & & Good & Poor & & \\
\hline Coffee & High & $10(19.61 \%)$ & $41(80.39 \%)$ & 1.14 & 0.48 \\
\hline consumption & Low & $11(25.58 \%)$ & $32(74.42 \%)$ & $(0.53-3.73)$ & \\
\hline
\end{tabular}

The results of the analysis show that sleep quality and coffee consumption have a relationship that is not statistically significant with a PR value of $1.41,95 \%$ CI: $0.53-3.73, \mathrm{p}=$ 0.48. Based on the value of the confidence interval which includes number 1 , coffee consumption cannot be concluded as a risk factor for the quality of poor sleep in nurses

Bivariate analysis of marital status variables with sleep quality in this study found that married subjects had a risk of 5.53 times experiencing poor sleep quality compared to 
unmarried / no partners. The relationship of this variable was statistically significant with a value of $\mathrm{p}<0.05$.

Research by Tahyeb et al. shows, that as many as $59.62 \%$ of married subjects experience poor sleep quality. In a study of 607 nurses in Malaysia it was reported that married nurses experienced more sleep disruption than those who were not married [1]. Different results were obtained in a cohort study conducted by Troxel et al. It was found that married women or couples had better sleep quality than women who did not have a partner because they were not married, divorced or separated. The study emphasizes that the stability of relationships in the household has a good impact on sleep. This is due to the psychological influence in which women feel safe and protected by the existence of spouses [7]. Sleeping with a partner and the quality of relationships in a marriage have an impact on the quality of their sleep. The presence of sleep partners (husband or wife) and good relationship in the household tend to reduce the incidence of sleep disorders [8].

The results of research conducted by Asghari et al. (2012) in Iran shows that widows give a high PSQI (Pittsburgh Sleep Quality Index) score. This indicates that widows are more likely to experience sleep disorders than married women [9]. In the terms of physiology, women who have poor-quality relationships with their husbands are reported to experience dysregulation of the hypothalamic-pituary-adrenal axis (HPA axis) which has an impact on increased corticotropin-relasing hormone $(\mathrm{CRH})$. This event is responsible for the alertness to cause sleep disturbances, such as insomnia. Besides that, disharmony in a relationship also risks increasing sympathetic nerve activity during the night, thus contributing to the incidence of sleep disorders [7]. The results of bivariate analysis of toddler ownership with sleep quality found that subjects who have no toddler had a risk of 3.88 times experiencing poor sleep quality compared to subjects who had toddlers. But the relationship between these two variables did not reach statistical significance with a value of $\mathrm{p}<0.05$.

In a study conducted by Cahyati (2014), $82.6 \%$ of those with toddlers experienced poor sleep quality, respondents in the study said they often woke up in the middle of the night due to the crying of their babies. Based on this study, subjects who were married and had toddlers admitted that their assignments were increasing, such as taking care of family and children, especially subjects who had toddlers. In a study in Malaysia it was reported that married nurses experience more sleep disorders than unmarried nurses. This is related to the responsibility of nurses to take care of the family, especially nurses who have children [1].

Bivariate analysis of work systems with sleep quality found that subjects with shift work systems had a risk of 19.46 times experiencing poor sleep quality compared to subjects with non-shift work systems. Research by Safitrie and Ardani (2013) reported that $64.7 \%$ of nurses with shift work systems had poor sleep quality. In the Asian region, it is reported that $57 \%$ of nurses with the shift work system experience impaired sleep quality. Sleep disturbances due to the shift work system are associated with changing sleep times so that the body is forced to adapt different sleep durations [4].

Research on nurses in Malaysia showed that sleep disorders were more prevalent in nurses with the shift work system than nurses with non-shift work systems even though the study had no significant difference [10]. The shift work system is thought to be one of the triggers for changes in the body's circadian rhythms where an internal desynchronization process occurs (desynchronization of the circadian rhythm) which then contributes to the emergence of various physiological and psychological disorders in shift workers [8].

Night shift increases the risk of sleep disorders. Another study conducted by Flo on 1,968 female nurses showed that one-third of the samples, amounted to 726 nurses, experienced symptoms of sleep disturbance, which most of them were nurses with the night shift work 
system [11]. In addition, night shift workers tend to sleep in the morning or afternoon and are reported to experience shortening of the sleep duration that is suspected due to noise in the morning or afternoon [12]. Excessive sleepiness is also found in shift workers, especially the night shift. The causes for this include long and irregular work schedules, and fast rotation of work schedules [13].

Sleep environment includes a variety of things including noise, temperature, lighting, etc. that are reported to have an impact on sleep quality. Noise is defined as unwanted sounds, subjectively disturbing and can cause physiological and psychological stress [14]. Light affects the internal clock through light-sensitive cells in the retina of the eye. These cells inform the brain about day and night, until then our sleep patterns are formed. Lamps that are too bright can cause sleep disturbances and inhibit melatonin secretion [15]. So that in a dark atmosphere someone falls asleep faster.

Research by Drake et al. reported the incidence of reducing total sleep duration by 1.2 hours on respondents who were tested for consuming caffeine $400 \mathrm{mg}$ at 0,3 and 6 hours before going to bed proved to reduce total sleep duration by 17.2 minutes found to be significant in caffeine consumption 3 hours before bedtime [17]. From the research conducted by Liveina (2014) about the relationship of consumption patterns and side effects of caffeinecontaining beverages to medical students at the Faculty of Medicine, Udayana University, it has also been proven that of $91.9 \%$ of respondents who drank coffee, $76.1 \%$ claimed experience side effects such as sleeping difficulty.12 Research conducted in North Sumatra showed that sleep quality was poor in $73.3 \%$ of people who consumed coffee [13].

Coffee is a source of caffeine that is widespread and can be obtained easily, in addition to other products such as energy drinks, cocoa and soft drink [14]. The main mechanism of caffeine can cause sleep disorders lies in the inhibition of caffeine against adenosine receptors. In maintaining homeostasis, adenosine inhibits cholinergic neurons which normally are responsible for alertness in other words that adenosine plays a role in inducing sleep. Caffeine inhibits adenosine activity, allowing a person to stay awake longer (prolonged sleep latency). In other words, caffeine is a stimulant [12].

\section{Conclusions}

Researchers concluded that marital status, toddler-ownership and work systems have a relationship that is statistically significant with poor sleep quality and can be concluded as the risk factors for poor sleep quality in nurses at BRSU Tabanan. Whereas environment and coffee consumption have a relationship that is not statistically significant with sleep quality and cannot be concluded as a risk factor for poor sleep quality in nurses at BRSU Tabanan.

\section{References}

[1] Thayeb, Ricky et al., 2015. Gambaran Kualitas Tidur Perawat Dinas Malam RSUP Prof DR. R. D. Kandaou Manado. Jurnal e-Clinic vol 3.

[2] Caruso, C.C \& Hitchoock, E.M, 2010. Strategies for Nurses to Prevent Sleep-Related Injuries and Errors. Rehabilitation Nursing, 35(5): 192-197.

[3] Kaur, J \& Sharma, C, 2011. Exercise in Sleep Disorders. Delhi Psychiatry Journal, 14 (1): 133 137. 
[4] Chien, P.L, et al., 2013. Sleep Quality Among Female Hospital Staff Nurses. Hindawi, pp.1-6.

[5] Hasanah et al., 2013. Overview Shift Work And Of Sleep Patterns Disturbance Installation Patterns In Ward Nurse In Abdul Moeloek Hospital Bandar Lampung. ISSN 2337-3776

[6] Walker, A.J, et al., 2010. Sleep Quality and Sleep Hygiene Behaviors of Adolescents During Chemotherapy. J Clin Sleep Med,6(5):493-444.

[7] Asghari, A, et al., 2012. Suvjective Sleep Quality in Urban Population. Arch Iran Med, 15(2): 95-98.

[8] Nazatul, S.M, et al., 2008. Prevalence of Sleep Disturbance Among Nurses In A Malaysian Goverment Hospital and its Association with Work Characteristics. JUMMEC, 11(2): 66-71.

[9] Flo, E, et al., 2012. Shift Work Disorders in Nurses - Assesment, Prevalence and Related Health Problems. PloS ONE, 7(4): e33981

[10] Roszkowski, J.R \& Jaffe, F, 2012. Analyzing Shift Work Sleep Disorder. Dialogue and Diagnosis, 1-12.

[11]Zverev, Y.P \& Misiri, H.E, 2009. Perceived Effect of Rotating Shift Work on Nurses Sleep Quality and Duration. MMJ, 2191): 19-21.

[12] National Sleep Foundation, 2013. Healthy Sleep Tips. Available from: http://www.sleepfoundation.org/article/sleep-topics/healthy-sleep-tips

[13] Drake, C, at al., 2013. Caffein Effect on Sleep Taken 0,3, or 6 Hour Before Going to Bed", Henry Ford Hospital Sleep Disorders \& Research Center, 1-20.

[14]Liviena, Artini IGA, 2014. Pola Konsumsi Dan Efek Samping Minuman Mengandung Kafein Pada Mahasiswa Program Studi Pendidikan Dokter Fakultas Kedokteran Universitas Udayana. Bali: Departemen Farmakologi Fakultas Kedokteran Iniversitas Udayana. Skripsi.

[15] Daswin, Nurdiana \& Samosir, 2009. Caffeine Effects Toward Sleep Quality of Students of Faculty of Medicine Universitas Sumatera Utara. Universitas Sumatera Utara

[16] Bawazeer N A, AlSobahi N A, 2013. Prevalence and side effects of energy drink consumption among medical students at Umm Al-Qura University, Saudi Arabia. International Journal of Medical Students 1(3):104-8.

[17] Belenky, G, 2013. "Caffein and Sleep", (National Sleep Foundation). Available: hhtp://www.sleepfoundation.org/article/sleep-topics/caffein-adn-sleep. (Accessed: 2017, December 